\title{
Ecology of Religion
}

\section{A Hermeneutical Model}

The aim of this paper is to present the outline of a new hermeneutical model in ecology of religion. The researcher who first offered an approach called Ecology of Religion to the investigation of the relationship between the natural surroundings and the expression of religion in that same environment was the Swedish ethnologist and historian of religions Åke Hultkrantz. The increase of research on ecology in several disciplines during the last decade is enormous. The problems of our planet's pollution may play a part in this development. Not only did they raise the awareness of these problems but also eventually supported insight into the dependency and interrelation between phenomena and their contextual framework and by this turned the perspective from isolated entities to interactions within a system.

\section{The Hermeneutical Triangle}

The Hermeneutical Triangle (see fig. 1), which Valerie DeMarinis uses in her hermeneutical approach to critical caring, applied psychology and psychology of religion (DeMarinis 1993), provides an excellent basis for the fundamental questions which must be answered in order to ground the theoretical model for the ecology of religion.

The insight that world view and truth claims are operating in theoretical formulations shows the necessity for the basic sector in the hermeneutical triangle. Because this bottom layer directs our theoretical choices we can hope for coherence in theory only after having come to terms with the nature of beings and entities, and their processes of dialogue and interaction. The hermeneutical foundation shapes the frame for the questions we are going to ask in the approach and the interpretation of their answers likewise. Only after having grounded our assumptions on research in a realistic context, can we strive for a theory that will work. No researcher can escape her or his cultural context, but hopefully may increase awareness. 


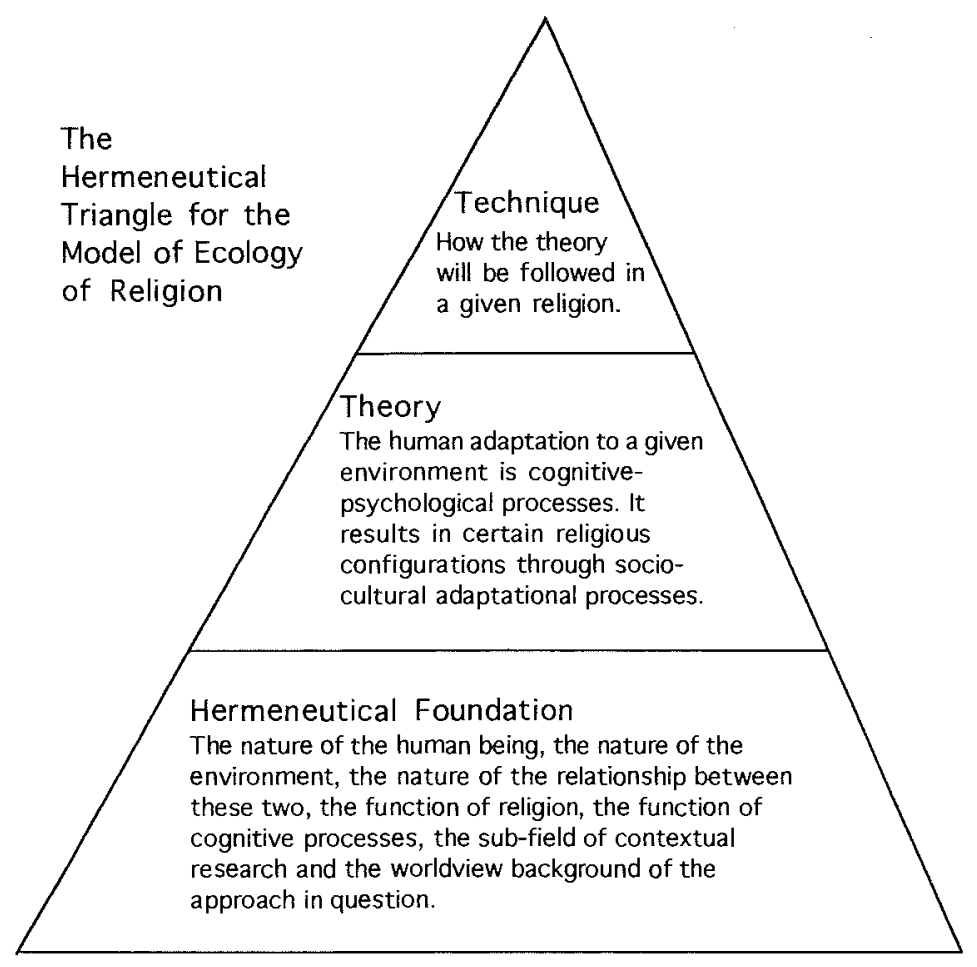

Fig. 1

Within the discipline science of religious studies several areas have developed over the last decades, such as the sociology of religion or the psychology of religion, and have established themselves as fields in their own rights. Our field, the history of religions, is not among these newcomers. It is traditionally dominated by historical and comparative research. Beside these two a third subfield, that of contextual research, is more and more observed. It is a subfield that profits from the results and methods of investigation in other disciplines, e.g., anthropology, ethnology, geology, and, especially in our approach, from cognitive psychology, linguistics and ecology. Cognition and adaptation are two keywords which we need in order to orient us regarding the relationship between context and religion. A cognitive psychological perspective as a broad explanatory category will be followed in the investigation. Religion as lived by human beings is the focal point. This involves several questions. We have to investigate the function of religion, the nature of the environment, and the nature of the human being. We have to ask: what is the nature of the relationship which connects people to their world? 
After having prepared the broad hermeneutical foundation, we shall be ready to enter the second sector of the hermeneutical triangle and create a model of the ecology of religion. The theory aims to understand human adaptational processes to a given environment as conditions for spiritual survival which can take form in religion.

Here the term "ecology of religion" serves as an umbrella to unify different methodological tools which are needed. As the term ecology implies, what is at issue is the impact of the environment on religion investigated through the interrelation between living organisms and their environment. From the fact that the subfield is defined as contextual research, it follows that the environment is principally a nonreligious context.

The model consists of two sectors. One is the material condition of the environment which forms the cultural core as reality that is coped with through religion. By taking over Julian H. Steward's method from cultural anthropology and making it suitable for religion, Åke Hultkrantz (Hultkrantz 1966; Hultkrantz 1987) created his ecology of religion. This was thought as a complementary perspective to already existing diachronic methods within the history of religions. The advantage of Hultkrantz' ecological model is that he follows Steward in his basic assumption that adaptational processes are creative processes, and that he extricates the synchronical features from a given religion. Hultkrantz' ecological approach is partial. The ecological factor is only one possible cause of change and adaptation, beside historical influences and cultural diffusion. What Lauri Honko rightly observes is that the analysis proceeds from the material foundations of society and not from the world view of the individual (Honko 1985: 59). What belongs to the religious core is not so much a matter of choice but one of priority. One could call it with Svein Bjerke "the religious aspect of the cultural core" (Bjerke 1979: 239). This will remain the sociocultural part in our model.

The sociocultural aspects are slightly modified but most of all complemented by the other sector in our theory, which is the cognitivepsychological part. This deals with the embodiment of the environment, which leads to cognitive processes, that is, categorization and ritualization. These serve as resources to create our illusionistic world, that is in our context, religion. The term "illusionistic world" has been taken over from Paul W. Pruyser. He coined it for the "third world" which in this context lies between the inner world of our fantasies and the outer world of external things:

The third world I am trying to define is the world of culture, i.e., the psychic and social "space" reigned by ideas that man lives by 
in his search for meanings. To set this world off from the other two, it can be described as the illusionistic world, for the symbolic entities germane to this world are properly definable as illusions. (...) Illusion includes mystery: since it is beyond the merely subjective and the merely objective, it has a special object relationship endowed with many surplus values about whose legitimacy one cannot bicker in terms derived from either the subjective or the objective (Malony and Spilka 1991: 166)

Although the term "illusionistic" is problematic in association with religion, it is adequate for the world to which symbols and imaginative and creative forces belong. Illusion grows out of imagination and has nothing in common with hallucination. Moreover, it is sketched by Pruyser as space between autistic dreaming and realistic working where people can engage in symbolic actions, shared with and supported by others. The term "illusionistic" depicts the qualities of this area as a world which is created by cognition and, once we have made the effort to free the word from its slightly negative overtones, the term will work well within our cognitive-orientated research.

The top of the hermeneutical triangle is occupied by technique, that is, the application and interpretation of our theoretical model for a given religion in a given environment.

\section{Hermeneutical Foundation}

\section{Frame of reference for the approach}

Our approach is placed within the field of history of religion. It is best understood as the subfield for contextual research. Although the environment is seen as a concrete physical entity, the research aims at an adaptation to this same environment which will turn it into a religious perceived one, that we usually call creation. This follows the principle of contextual research as Jacques Waardenburg outlined it. He characterizes this type of research through its main task, that is, to exemplify empirical coherence between religious forms and their context ${ }^{1}$. In contrast to investigations of social and historical contexts, which so far dominate the field, it is the context of the natural

\footnotetext{
${ }^{1}$ Waardenburg 1986: 145 "...der kontextuellen Forschung geht es ganz besonders darum, konkrete nachweisbare Zusammenhänge zwischen einer religiösen Gestaltung und dem Kontext, in dem diese auftritt, aufzuzeigen und nach Möglichkeit Erklärungen für diese Gestaltung zu liefern."
} 
environment that is studied here. To this fact the approach owes its title and is therefore called the Ecology of Religion.

Historically the term ecology grew out of the discipline of biology. Ecology, a term introduced by Ernst Haeckel (1834-1919) to signify the relationship between biological organisms and their environment, was employed by this Darwinist for adaptational processes. From this follows that we can find that scientific literature on ecology still reduces every organism, the human being included, to a biological entity, both as an individual or a social body as is the case in Roy A. Rappaport's Pigs for the Ancestors (Rappaport 1968), and, that evolutionistic ideas still play a part in so far as they ascribe the main influence in adaptational processes to the environment as observable in Åke Hultkrantz' ecology (Hultkrantz 1966).

We do not agree with the world view that allows the use of the term ecology in Darwinism and Evolutionism. Adaptational processes of the human being are not identical with such processes in the domain of other biological organisms. That would mean to treat the cultural dimension of existence as if it had emerged through a series of events in the phylogenetic history of the human species. Neither can we support a world view which neglects the activity of the human being in cultural processes. Thus focusing on the result, that is, cultural achievements as if they had a life of their own, leaves the actor out and by this the empirical root of culture as something that is lived. Studying mutual relations and circular processes we have to observe the organisms themselves which share in the interaction, instead of making them a silent prerequisite. Therefore it is necessary to introduce the human beings themselves in the model.

The orientation for ecology of religion, as represented here, is the investigation of the direct interrelation of the human being, actor in all cultural processes, with the natural environment. If it were our intention to reduce human nature to a biological organism, then we could place our approach in the field of biology. But, because it is our intention to show that the human being by nature is essentially one that lives a religion and is enabled to do so through cognitive processes, it is cognitive psychology that offers the orientation for our research.

\section{The nature of the environment}

Because human beings are born into a given environment they exist in it and are surrounded by it in all directions, both vertical and horizontal. In our approach environment means the natural surroundings, topography, biotope, climate, natural phenomena and natural 
resources in an area that people can interact with. But the environment is not identical with the physical world. Environment is something human beings relate to and it becomes their world first through this relationship. It is a world-as-interacted-with. This outer world comes into existence the very moment one is aware of oneself as an individual body. The properties which are relevant to the building of cognitive schemata are the interactional properties which derive from the classifier's interaction with the category. Likewise, in the ritual process it is the social body which creates the ritual space.

The environment as an entity is indivisible and continuous. It is essential for our approach to regard the environment as a whole in which the human being is integrated. The paradox we have to live with is that human beings are already occupying a place in an outer world while they are looking for a place in it in order to cope with this outer reality.

The environment is a unity highlighted rather than structured by the immediate situation which is identical with our point of view at that moment. We can compare it to the different views seen from a valley as compared with them from the hilltop. The landscape remains the same but our views have been very different. The unity is structured by complementary fields analog to the patches in a picture where every patch gets its significance through the surrounding composition. On the level of language it is expressed in James F. Weiner's words:

The conventional status of any form of discourse is not ... a function of its role in underpinning or expressing a conceptual system, but is situationally determined only in relation to all other forms of discourse (Weiner 1994: 595)

\section{The nature of the interrelation}

The world around us is a unity which becomes structured by cognition. It is experienced as a picture in which nothing is isolated, but structured in a way that allows for complementary interrelation. Complementary means difference but not opposition. The interrelation between things does not need to be antagonistic. Compared to other world views, like the one which underlies Structuralism, the relationship between parts of the world is not the one of binary oppositional pairs. Rather, the relationship is an organic one in which each part accomplishes the organism. Human beings are part of this organism because of being situated within the environment. 
This basic setting provides the circumstances for the interaction between people and their environment. What is at man's disposal to relate to the world around? It is the body.

The body follows the same principle of holistic interpretation as the environment does. It is seen as a unity that is indivisible although it can be viewed from different angles and, of course, different functions or parts of it can be highlighted. The human being does not have a body but is a body. In our investigation several aspects of the body will be emphasized while having in mind the concept of the body as unity.

Embodiment is an act of integration of experience. The fact that all processes by which the human being acts - as part of his world are located in the body, makes the body an incarnation of our experiences. The processes through which human beings become aware of their environment are cognitive. Cognition is an act of knowing. Embodied image schemata form the elements by which understanding is built up in the conceptual system. Mark Johnson uses image schemata for an embodied, relative simple structure of spatio-temporal experience. This internal structure of image schemata is a Gestalt structure. That means they are coherent meaningful unities in our cognition which connect many different aspects of our experience. As Gestalt structure they are irreducible and as such constrain the way in which the schema organizes meaning. But as schemata they are malleable, too. It is a recurring, dynamic pattern of our perceptual interactions and motor programs that gives coherence and structure to our experience (Johnson 1987: 3). Because our bodies are very much alike we can assume commonly shared Gestalt structures for most of our physical interactions within our environment.

Johnson mentions bodily movement, manipulation of objects, and perceptual interactions as examples for embodiment. All three of these experiential processes are rooted in the body's position, viz. our upright position on two legs which enables us free hands to handle objects and a certain eye-level. Johnson's list of the most common image schemata shows this clearly. E.g.: as a being in an upright position we employ balance with reference to a vertical axis. Our panoramic view makes us the center of a world which radiates from our bodies. We are the starting point in a path schema etc. All human spatial-temporal experience is relative to the human being's size as old measurements e.g.: foot, a man's height, etc. show.

All human interactions with the environment like moving, manipulating objects, and eating are basic, they are natural kinds of experience because they are products of the human nature (Lakoff and Johnson 1980: 177). The body orders and organizes the environment 
which is experienced into a world that can be identified. Categorization as Mark Johnson and George Lakoff (Johnson 1987; Lakoff 1990; Lakoff and Johnson 1980 ) have represented it and ritualization in Catherine Bell's (Bell 1992) understanding of the term are processes not only to take the outside in. They, too, are instruments to connect these experiences within the body to use them in further structuring and identification of the outside.

Through its physical movements the body gives structure to the environment, giving way for understanding through ritualization. Ritual is a kind of activity in its own right. Central to it is the body which has its own way of knowing and functioning. The body as a social person is emphasized in aspects which constitute the human being as someone in whom the primacy of the body is responsible for categorization, in whom the body is the place for the social construction of reality, and in whom the body is the center for a person's lived experience. The logic of ritualization is embodied in physical movements of a body which is always conditioned by a certain context. This context is the structured and structuring environment. Bell is stressing this situational quality of ritual because it is crucial for her understanding of ritualization as a mutual interaction of the ritual body and the environment.

She asks first in what way does ritual distinguish itself from other practices. To answer this question she elaborates four characteristics of human activity. Firstly, human activity is always situational, that means the frame of reference is the specific context where it occurs. Secondly, it is strategic, as a real activity in time, it is a practical performance of effective schemata. Thirdly, human activity is embedded in a misrecognition of what it is in fact doing, that is, the intentional strategy of an action is dominating the material performance and is that what is seen by the participants. And fourth, the motivation, which is integral to the context of action, is able to reconfigure a vision of the order of power in the world. Ritualization might be denoted as the very activity which brings people into contact with those forces they believe to be real. Ritualization distinguishes itself from other practices because it is for people a practical way of becoming aware and of dealing with some specific circumstances. The important actors in this process are the social body, which generates the environment as a ritual space and the environment which, so structured, molds the body into a ritual one:

By virtue of this circularity, space and time are redefined through the physical movements of bodies projecting organizing schemes on the space-time environment on the one hand while reabsorb- 
ing these schemes as the nature of reality on the other (Bell 1992: 99).

Bell describes the process of interaction between the social body and the environment analogous to Bourdieu's idea of this dialectical relationship:

It is in the dialectical relationship between the body and a space structured according to mythico-ritual oppositions, that one finds the form par excellence of the structural apprenticeship which leads to the em-bodying of the structures of the world, that is, the appropriating by the world of a body thus enabled to appropriate the world (Bell 1992: 98)

This molded body is equipped with a "sense of ritual", an internalized practical knowing for the way in which things are done in a specific cultural context, a know-how that produces ritualized social agents, in which schemata for nonritualized situations, to render them more coherent with the values of the ritualizing schemata are embedded. This chain reaction, called by Bell "ritual mastery" makes ritualization an activity which involves the entire person and this person's whole environment.

To investigate the relation between environment and body is to look for bodily actions which take up dominant structures in the environment to use them in order to relate to it. Concepts which are built on spatio-temporal experience are a means of communication through speech actions. Rituals which employ structures from the environment are a means of communication through bodily performed actions.

\section{Adaptation}

Ecology of religion focuses on the human actor as a religious person. To understand the form that a religion takes in a given natural environment it is necessary to study the interrelation of body and environment. It is equally important to regard the human being as an actor who wants to survive under given environmental conditions.

For our approach the function of the human-environmentrelationship is regarded as adaptation. Human operations which are exercised in order to survive can be denoted as adaptational processes. Adaptation is as much assimilation as adjustment. It starts with the embodiment of structures and schemata which are dominant in a given environment. In opposition to Darwinism, adaptability is not something given which, being either successful or doomed to failure, results in the selection of the successors as survivors. In 
ecology of religion adaptability is created through the interaction of the body with the environment. Through embodiment and its associated operations, that is, ritualization, categorization, and the creation of the illusionistic world, the human being becomes adapted to the environmental macro-organism. That turns cognition itself into an adaptational operation.

This kind of relationship is in line with complementary interrelations in two respects. In the first place, because the processes involved are circular, it is through reformulation that they are creating adaptability in the human being. Secondly, because the environment and the human actor are an inseparable pair, they complement each other. It is the world as an entity and the adaptability of the body that provide the opportunity for human adaptational operations. They enable the human being to maintain a complementary interrelation, the kind of relationship that nurtures the ontology underlying our approach. Adaptation will be understood as strategy to keep this complementary relation between micro- and macro-organism intact.

To summarize: So far we can point to a world view which underlies our approach, that is, the world is viewed as a whole, consisting of complementary parts which are characterized by their relations. The human being is included in the macro-organism and equally related to it in a complementary manner. Adaptability is created through this relationship by embodiment of the environment and associated cognitive processes. The relationship is characterized by the centrality of the body.

Adaptational operations are regarded as those that are performed to secure material and spiritual survival. By material survival we think of all needs to physically uphold our body, like shelter and food. Spiritual survival includes all operations that support the sense for life in a non-materialistic way. The latter need not necessarily take the form of a socially shared religion although in our approach we are investigating this collective form. Spiritual survival means to turn the physical orientation in the environment into an immaterial one.

The natural environment serves in human adaptation as medium for spatial-temporal experience, as material circumstance that allows for certain kinds of production or sustenance activities, and as physical display that lays out its forms, objects and phenomena ready for people's symbolic perception.

Adaptational strategies are equally employed on the spiritual and the material level. Ecology of religion focuses on spiritual adaptation. The human cognitive-psychological processes are viewed as strategies for a person's spiritual survival and are indispensable to describe adaptational operations of the human being. The human dependency 
on material needs gives rise to sociocultural adaptation, which is viewed as a strategy for people's spiritual survival, too. The latter is necessary to understand adaptational processes that result in certain religious configurations.

\section{Religion}

Our concern is religion as it is lived by human beings in a given environment. These three components together form an associative structure. Religion is viewed as a condition for spiritual survival of human beings who are participating in a common environment. To fill this function religion must be responsible for the world view through which people can find and maintain their place in the world. That religion accounts for a peoples' identity and ethnocentrism is a consequence of this function.

Spiritual adaptation to the natural environment as function of religion is a perspective we are not familiar with, although the definition of religion as a world view, through which people can find and maintain their place in the world, implies the question after the impact of the physical world on the religious one, too. It is the experience of the environment in combination with the material and the spiritual needs and their symbolism that is responsible for the forms by which religious contents are lived and communicated. In other words, environment is one of the factors that is responsible for what a religion looks like.

\section{The nature of the human being}

How do we understand the human nature in the world which we have described? Until now, we have taken up the relationship and its different aspects, being complementary, bodily, and adaptational, that bind human beings to their world. We have touched on the issue of making sense of the environment people find themselves in. Further, we have introduced the paradox that people, already existing in a given habitat, have to anchor their existence in the world, that is, to find a place and root themselves in it. This essential matter of survival is what we call religion. It is an expression of life. It is the human nature to be religious.

Central to the human nature is the body that enables people to be connected sensitively, physically, and cognitively to their environment. This connection is responsible for the human awareness of being in the world, which is central to human nature in our ontology and for our approach. This being in the world is constantly recurring at all levels of human relations between people and their environ- 
ment: They view the world in pictures, very often even appearing as part of it. Through embodiment the experienced structures of the environment become their own basic structures in acting and in reasoning. Human beings relate their identity to this spatial and temporal unity and last but not least they refer emotionally to their world as a whole.

In order to live, this experienced outer reality must become a matter for the religious person. The world must be turned into a personal world for the believer. The autistic world is the inner force to carry out this transformation from a realistic into an illusionistic, that is, religious world. What Pruyser named the "autistic world" is constituted by the psychical inner forces, e.g.: fantasy, free associations, and ineffable images, that lie within the human nature in a somewhat raw, untamed condition. When these forces struggle with reality a third psychological realm is put forward in order to cope with reality while maintaining the person. Cognitive processes, that is categorization and ritualization, are the adaptive operations by which the autistic human being creates the illusionistic world in which symbolic and social action are possible. It is the world of culture that human beings need as condition for spiritual survival. It is the world they live in. By this, the non-religious context is given the status of a theoretical assumption as a world in which religion is possible, though not-yet realized by human interaction. The experience of being rooted in the world, or, in our words to be a complementary part in a meaningful whole, is not given once for ever but an ongoing process where making sense of the world is continually adjusted to the environment. To maintain spiritually a place in the world involves operations on two levels. The human being has to secure it both by strengthening the illusionistic world and by a practical, lived way through the realization of religious concepts and the performance of rituals.

\section{References:}

Bell, Catherine

1992 Ritual Theory, Ritual Practice. Oxford: Oxford University Press.

Bjerke, Svein

1979 Ecology of Religion, Evolutionism and Comparative Religion. In: Lauri Honko (ed.), Science of Religion: Studies in Methodology; pp. 237-248. The Hague: Mouton. (Religion and Reason, 13) 


\section{DeMarinis, Valerie $\mathbf{M}$.}

1993 Critical Caring. A Feminist Model for Pastoral Psychology. Louisville, Kentucky: John Knox Press.

\section{Honko, Lauri}

1985 Rethinking Tradition Ecology. Temenos 21: 55-82.

\section{Hultkrantz, Ake}

1966 An Ecological Approach to Religion. Ethnos 31: 131-150.

1987 Ecology In: Mircea Eliade (ed.) The Encyclopedia of Religion; vol. 4; pp. 581-585. New York: Macmillan.

Johnson, Mark

1987 The Body in the Mind: The Bodily Basis of Meaning, Imagination, and Reason. Chicago: The University of Chicago Press.

Lakoff, George

1990 Women, Fire, and Dangerous Things: What Categories Reveal about the Mind. Chicago: The University of Chicago Press.

Lakoff, George, and Mark Johnson

1980 Metaphors We Live By. Chicago: The University of Chicago Press.

Malony, H. Newton, and Bermard Spilka

1991 Religion in Psychodynamic Perspective: The Contributions of Paul W. Pruyser. New York: Oxford University Press.

Rappaport, Roy A.

1968 Pigs for the Ancestors: Ritual in the Ecology of a New Guinea People. New Haven: Yale University Press.

\section{Waardenburg, Jacques}

1986 Religionen und Religion. Berlin: Walter de Gruyter (Sammlung Göschen, 2228).

Weiner, James $\mathbf{F}$.

1994 Myth and Metaphor. In: Tim Ingold (ed.), Companion Encyclopedia of Anthropology; pp. 591-612. London: Routledge. 